This is an Accepted Manuscript of an article published by Taylor \& Francis Group in Latin American and Caribbean Ethnic Studies on 10 Jun 2020, available online: http://www.tandfonline.com/10.1080/174442222.2020.1770986

\title{
"Nosotras le llamamos acompañamiento": las dirigentas quechuas y aimaras del sur peruano y la interpretación ad hoc
}

Raquel de Pedro Ricoy

Faculty of Arts and Humanities, University of Stirling, Pathfoot Building, Stirling FK9 4LA, Reino Unido. E-mail: raquel.depedroricoy@stir.ac.uk

Catedrática de Traducción e Interpretación. Sus intereses se centran en las dimensiones sociales y culturales de la traducción e interpretación, especialmente en contextos que implican a comunidades minorizadas, y en la traducción de textos multimodales. Además de publicar numerosos artículos sobre estos temas, ha dictado conferencias magistrales y presentado ponencias sobre los mismos en América, Asia y Europa.

Rosaleen Howard

School of Modern Languages, Newcastle University, Claremont Road, Newcastle-UponTyne, Tyne and Wear NE1 7RU, Reino Unido. E-mail r.e.howard@ncl.ac.uk

Catedrática de Estudios Hispánicos y Directora del Centro de Estudios Latinoamericanos y Caribeños de Newcastle University. Trabaja sobre sociolingüística y antropología lingüística de los Andes. Sus publicaciones incluyen Por los linderos de la lengua. Ideologías lingüísticas en los Andes, Lima: IEP/IFEA/PUCP (2007) y Kawsay Vida. A Multimedia Quechua Course for Beginners and Beyond, Austin, TX.: University of Texas Press (2013).

Raquel Reynoso

Asociación Servicios Educativos Rurales, Jr. Domingo Ponte 840, Magdalena del Mar, Lima 15076, Perú. E-mail: raquel.reynoso@gmail.com

Trabajadora Social con 20 años de experiencia laboral en espacios de acompañamiento, promoción y defensa de derechos humanos, orientada por los enfoques de interculturalidad y género. Especializada en Estudios de Paz, Conflictos y Desarrollo.

Luis Andrade Ciudad

Departamento de Humanidades, Pontificia Universidad Católica del Perú (PUCP), Av. Universitaria 1801, Lima 32, Perú. E-mail: lfandrad@ pucp.edu.pe

Profesor asociado de Lingüística en el Departamento de Humanidades de la PUCP. Se interesa por la lingüística andina, la lingüística de contacto, la lingüística sociocultural y la sociolingüística histórica. Ha publicado recientemente El castellano andino norperuano. Una historia lingüística y social (Lima: Fondo Editorial de la PUCP / Instituto de Estudios Peruanos, 2019).

Este artículo analiza la interpretación ad hoc en un contexto de colonialidad multilingüe desde perspectivas sociolingüísticas y etnográficas. Se centra sobre la mediación lingüísticacultural que realizan rutinariamente dirigentas bilingües de Ayacucho y Puno para facilitar 
la comunicación entre miembros de sus comunidades (hablantes de quechua y aimara) y los/las funcionarios/as estatales (por lo general, hablantes monolingües de castellano). A diferencia de los/las traductores/as e intérpretes indígenas acreditados/as por el Estado peruano, estas mujeres no cuentan con formación en interpretación y cumplen sus funciones de manera voluntaria y sin remuneración. Para abordar de forma crítica el desempeño de estas intérpretes ad hoc, contextualizamos su labor en la coyuntura del Perú contemporáneo $y$, desde una perspectiva histórica, la relacionamos con la literatura especializada referente a la interpretación ad hoc. Mediante los testimonios de las dirigentas, que recopilamos en un trabajo de campo durante 2018, ilustramos los retos que enfrentan, así como sus logros y sus motivaciones. El análisis de los datos nos permitió examinar los vínculos entre la mediación lingüística-cultural y la autoidentificación étnica y comunitaria de las participantes, así como la manera en la que sus prácticas de mediación son percibidas por los actores estatales y los miembros de sus comunidades.

Keywords: derechos humanos; dirigentas indígenas; interpretación ad hoc; lenguas indígenas; Perú; servicios públicos

\section{Introducción}

En un país como el Perú, con una gran diversidad lingüística y limitada infraestructura de transporte y comunicaciones en áreas rurales y remotas, se producen cotidianamente situaciones en las que resulta difícil, si no imposible, contar con la presencia de intérpretes y traductores capacitados por el Estado. ${ }^{1}$ Accidentes, emergencias médicas, mediaciones en juzgados de paz, talleres de capacitación y llenado de formularios o planillas para las instituciones públicas son algunos ejemplos de realidades en las que las personas con escaso o nulo conocimiento del castellano pueden verse frenadas en el cumplimiento de sus derechos ante servidores públicos que son hablantes monolingües de este idioma.

Este artículo se centra en la labor de un grupo de dirigentas (es decir, lideresas de organizaciones sociales), hablantes de quechua y aimara, de Ayacucho y Puno, que rutinariamente asisten a miembros de sus comunidades en circunstancias como las descritas anteriormente. Su actividad de mediación lingüística y cultural incide de manera crucial en la protección de los derechos humanos de las personas a quienes apoyan. A lo largo de 2018 desarrollamos un proyecto de incidencia social en el que las dirigentas fueron protagonistas, tanto a la hora de perfilar el programa de actividades, como mediante su participación en ellas. La intención fue visibilizar su rol como mediadoras lingüísticas y culturales, que llevan a cabo sin remuneración y sin haber recibido formación y que, a menudo, pasa desapercibido para el Estado y la sociedad en general. De hecho, algunas manifestaron que no sabían que su trabajo para posibilitar el entendimiento entre los castellanohablantes y los hablantes de quechua y aimara era 'traducir,' dado que es algo que hacen de manera cotidiana y natural. Nos centramos en dirigentas porque la Asociación Servicios Educativos Rurales (SER), ${ }^{2}$ socia del proyecto, informó que es más frecuente que este tipo de labores las realicen mujeres que varones. ${ }^{3}$

El objetivo del artículo es elucidar cómo se desarrollan las labores de interpretación ad hoc en la zona andina del Perú al margen de la intervención estatal. A partir de este objetivo, pretendemos dar respuesta a las siguientes preguntas: (i) ¿en qué medida las intérpretes y traductoras ad hoc entre quechua y aimara, por un lado, y castellano, por otro, se inscriben en la caracterización del rol que se ha hecho en la literatura especializada?; (ii) ¿qué 
relación existe entre el ejercicio de dicho rol y la autoidentificación étnica y comunitaria de las dirigentas?; (iii) ¿cómo perciben estas mujeres las actitudes respecto a las prácticas de mediación que desarrollan por parte de los agentes estatales y de los miembros de sus propias comunidades?; y (iv) ¿cómo contribuye la labor de las intérpretes ad hoc a la defensa de los derechos humanos lingüísticos de los miembros de sus comunidades?

Para ello, sobre la base de un estudio de campo, examinaremos la información proporcionada en forma de testimonios y entrevistas por dicho grupo de dirigentas, partiendo del supuesto de que es representativa de la situación existente en otras áreas del país, a pesar de las diferencias dictadas por especificidades históricas, como los niveles de violencia sufridos en Ayacucho durante el periodo 1980-2000, contexto al que nos referiremos después. Nuestro estudio ha sido desarrollado por un equipo interdisciplinario que combina experiencia teórica de la interpretación comunitaria y de la sociolingüística histórica y contemporánea con la experiencia práctica del trabajo social dedicado al apoyo de las poblaciones indígenas del Perú. Así, buscamos abrir nuevas perspectivas respecto a la interpretación ad hoc en un contexto de colonialidad ${ }^{4}$ que tiene relevancia en el marco de los estudios de corte sociolingüístico y etnográfico.

Con la emergencia de programas de formación en traducción e interpretación con lenguas indígenas en Latinoamérica en el siglo XXI, han comenzado a publicarse trabajos respecto a la provisión oficial de tales servicios y a las intervenciones de los/las traductores/as e intérpretes indígenas profesionalizados/as. No obstante, el desempeño de los/las intérpretes ad hoc, que tradicionalmente se ha estudiado desde una perspectiva histórica, sigue siendo un gran desconocido en contextos contemporáneos. Aunque la interpretación ad hoc ya ha sido abordada en otras publicaciones, hasta el momento escasea la investigación empírica sobre ella en Latinoamérica, en general, y en el Perú, en particular (como excepción, véase Schneider 2015). Con nuestro trabajo empírico, que aborda el tema desde la perspectiva de sus protagonistas, pretendemos contribuir a llenar un vacío en la literatura especializada.

Comenzaremos presentando algunas reflexiones sobre el uso de la terminología pertinente a la conceptualización del desempeño de estas mujeres y a las categorías identitarias relevantes. Tras exponer la metodología del proyecto, pasaremos a contextualizar la labor que realizan: quiénes son y de qué manera actúan como mediadoras entre lenguas y culturas en sus roles de dirigentas y de acompañantes, a veces en la intersección entre lo 'natural' y lo oficial. A continuación, revisaremos la literatura sobre el desempeño de los y las intérpretes ad hoc y del rol histórico de los intérpretes en el Perú colonial. En cuanto a este último, resultan interesantes los posibles paralelos de la distinción colonial entre la figura del intérprete general y los 'lenguas' con la que se está desarrollando en el Perú actual. Esta concierne a la diferenciación entre los y las indígenas formados como intérpretes por el Estado y las personas que, como las participantes en nuestro proyecto, carecen de capacitación y de un marco profesional reconocido. ${ }^{5}$ Luego ilustraremos estos presupuestos teóricos con los testimonios personales que recabamos a lo largo del proyecto, resaltando tanto los retos que enfrentan las dirigentas como sus logros, así como la incomprensión o incluso el rechazo que a veces sufren por parte de las autoridades con las cuales se relacionan en sus intervenciones. Concluiremos presentando una serie de reflexiones cimentadas en el trabajo realizado en el marco del proyecto.

\section{Reflexiones terminológicas}

Conceptualizar el rol de las dirigentas que es objeto de este estudio resulta complejo. Primeramente, la terminología que se maneja en la literatura sobre estudios de traducción e interpretación no se ajusta necesariamente a los términos descriptivos de su desempeño que 
utilizan ellas. Los términos 'traducción' (escrita) e 'interpretación' (oral) suelen usarse en referencia a actividades profesionales, excepto en el caso de la interpretación ad hoc, o 'natural, ${ }^{6}$ que se desarrolla al margen de la regulación en contextos específicos. En línea con los fundamentos teóricos de la interpretación, se puede asociar esta última a las labores de apoyo a la comunicación que desarrollan las dirigentas. Sin embargo, ellas se definen como 'acompañantes' y no siempre se identifican con el apelativo 'traductoras,' una denominación profesional que les es ajena. Raramente utilizan el término 'intérprete,' aunque su desempeño es oral, posiblemente porque no lo asocian a prácticas linguiísticas o porque 'traducción' comúnmente engloba la producción oral y la escrita.

En este sentido, resulta significativo que para referirse a las dirigentas en su faceta de intérpretes ad hoc SER utilice el término 'traductoras sociales', que obvia la distinción entre la oralidad y la escritura y destaca el importante aspecto social de su labor. Por otra parte, desde el Ministerio de Cultura del Perú (MINCUL) se ha manifestado la voluntad de reservar la denominación de traductores/as e intérpretes para aquellas personas que han cursado la formación facilitada por el Estado. ${ }^{7}$ Todo ello parece apuntar a que el desempeño de las dirigentas se considera como una mediación entre lenguas y culturas y no como interpretación, actividad especializada que está reglada y a la que se adscriben, correcta o incorrectamente, nociones como la precisión, la corrección y la neutralidad. En este artículo utilizamos los términos 'mediadoras' y 'mediación' en sus acepciones genéricas, sin identificarlos con la mediación cultural desarrollada por profesionales, que no implica necesariamente una transferencia interlingüística.

Las categorías identitarias que usamos a lo largo del texto buscan reflejar los términos que utilizan las participantes para referirse a sí mismas, como 'lideresa' y 'dirigenta' (este último es el más utilizado por SER), que enfatizan su función social y comunitaria. Aunque algunas de las organizaciones a las que pertenecen resaltan la adscripción étnica mediante la etiqueta 'aimaras' (en Puno, para las participantes aimaras) e 'indígenas' (en Ayacucho, para algunas de las participantes quechuas), en las entrevistas y grupos focales que analizamos aquí, estos significantes no aparecieron de manera prominente. En la sección histórica, sí utilizamos etiquetas de tipo étnico, como 'indígenas,' 'mestizos' e 'indios,' de acuerdo con lo encontrado en las fuentes documentales y los usos de la literatura etnohistórica. Cabe recordar que, actualmente, estas etiquetas étnicas son elusivas y cambiantes en las diferentes esferas de acción en las que participan los actores sociales en los Andes (De la Cadena 2004; Howard 2009), por lo que hemos preferido no adscribirlas nosotros como investigadores.

$\mathrm{Al}$ referirse a las personas a las que representan, las participantes usaron, entre otras, las etiquetas 'comuneros' y 'autoridades' para referirse a los miembros de las comunidades con las que interactúan en general, pero para los/las beneficiarios/as directos/as de su mediación, resaltan las categorías de tipo familiar: de manera prominente, 'hermanos' y 'hermanas,' así como 'mamitas,' que, en el castellano del sur andino, ha cobrado el significado de 'mujer mayor de origen campesino,' además de 'señoras.' 8 'Funcionarios,' 'profesionales' y 'empleados públicos' fueron los significantes más frecuentes al referirse a los agentes estatales con los que las dirigentas tienen contacto; 'personal de salud' aparece también de manera específica en el caso de este sector. Cuando las participantes se expresan en lengua indígena, algunos de estos significantes se mantienen en castellano, en particular, 'hermanos' y 'hermanas,' junto con los equivalentes ñaña 'hermana (de mujer)' y kullaka 'hermana (en general),' del quechua y el aimara, respectivamente.

\section{Antecedentes y metodología}


Nuestro proyecto de incidencia y concientización social surgió a raíz de un proyecto anterior enfocado en la formación estatal de traductores e intérpretes indígenas peruanos, en el marco del cual colaboramos con el MINCUL y con la Asociación SER. Gracias al contacto con esta última, supimos de las actividades de mediación desarrolladas por las lideresas ayacuchanas y puneñas, con quienes SER venía trabajando desde hacía más de veinte años. Así, nos planteamos la meta de que, mediante su participación en el proyecto y en las actividades relacionadas con el mismo, las dirigentas se sintieran empoderadas y valoradas por el importante papel que desempeñan para paliar carencias en la implementación de los derechos lingüísticos de sus comunidades.

La metodología para recopilar los datos que sustentan este artículo se basa en el principio fundamental del proyecto: la colaboración entre los investigadores, SER y las dirigentas en la construcción del programa de actividades. El protagonismo de estas últimas fue clave no solo para visibilizar y poner en valor su rol, sino también para identificar sus intereses respecto a cómo hacerlo. Se trata de 15 mujeres (11 de Ayacucho y cuatro de Puno). ${ }^{9}$ De ellas, 11 tienen como lengua materna el quechua y tres el aimara, mientras que una aprendió el quechua en su adolescencia. Sus edades fluctúan entre los 36 y los 65 años. Siete de ellas son casadas, dos son convivientes y seis son solteras. De estas últimas, solo dos no tienen hijos y todas las demás tienen entre uno y cinco hijos, la mayoría ya mayores de edad. Esta información es relevante en la medida en que tener a sus hijos adultos, salvo en dos casos, les ha permitido ausentarse de sus casas y participar con mayor facilidad en las actividades del proyecto.

La oficina de SER en Ayacucho organizó un foro el 1 y el 2 de marzo de 2018, facilitado por la presidenta de la asociación y los investigadores, para que las dirigentas de Ayacucho y Puno se conocieran y pudieran intercambiar experiencias. La meta del foro fue definir sus prioridades en cuanto a tres de las actividades propuestas por los investigadores y SER: una obra teatral, una exposición audiovisual y la grabación de materiales relativos a la mediación lingüística y cultural como legado para futuras generaciones. Esta meta se alcanzó mediante presentaciones individuales, debates grupales y sociodramas.

Para desarrollar las actividades según lo acordado, los investigadores realizaron dos rondas de entrevistas como parte del trabajo de campo, la primera en Ayacucho (23-27 de marzo de 2018) y la segunda en Puno (6-8 de abril de 2018). El objetivo fue entrevistar individualmente a las dirigentas en sus lugares de residencia o trabajo y recopilar sus testimonios, que formarían la base de la obra teatral, la exposición y los materiales recogidos en un repositorio digital. ${ }^{10}$ Tanto las entrevistas como los testimonios fueron grabados en video con la asistencia de un técnico audiovisual. ${ }^{11}$ A las dirigentas se les ofreció la opción de expresarse en castellano o en sus lenguas nativas (quechua y aimara). ${ }^{12}$

Las grabaciones fueron validadas por las dirigentas (11 de noviembre de 2018) de cara a su difusión. En el proceso de validación, vieron individualmente el video de su propio testimonio, acompañadas por los investigadores, tras lo cual dieron su consentimiento a que se hiciera público o expresaron su voluntad de que se omitiera algún fragmento. Las partes que nos solicitaron omitir, que fueron solo dos breves segmentos, no forman parte de los datos recogidos en este artículo ni en ninguno de los productos de acceso público que resultaron del proyecto. Dos de las dirigentas se vieron desbordadas por la emoción al exponer sus testimonios, lo cual planteaba un dilema ético a los investigadores. Tras la validación, ambas manifestaron que querían que la grabación se difundiera sin omisiones, para dar constancia de la dimensión humana de su rol.

Los aportes que hicieron las participantes en las entrevistas y los testimonios presentan un panorama muy rico y complejo de sus actividades de mediación linguiística y cultural, que incluye sus motivaciones para desarrollar dichas actividades de forma voluntaria, así como los obstáculos que encuentran. En este artículo, las propias palabras de 
las dirigentas nos servirán para ilustrar estos aspectos, conceptualizados con referencia a los estudios de interpretación no profesional y al legado de la colonización en el Perú.

\section{Las participantes en el proyecto y el contexto sociopolítico}

Cuando abordamos cualquier estudio en Ayacucho y Puno, surge de inmediato la referencia al conflicto armado interno que vivió el Perú entre 1980 y el 2000. El trabajo realizado con las dirigentas no es una excepción. Ayacucho fue una de las regiones más afectadas por la violencia, al igual que Puno, aunque en menor grado. Tal como señaló la Comisión de la Verdad y Reconciliación (CVR), este período fue "el episodio de violencia más intenso, más extenso y más prolongado de toda la historia de la República. Asimismo, [...] fue un conflicto que reveló brechas y desencuentros profundos y dolorosos en la sociedad peruana," siendo dos de ellos el racismo y la discriminación (Comisión de la Verdad y Reconciliación 2003, 315). ${ }^{13}$

Estas regiones hasta hoy reportan altos índices de conflictividad social y, a lo largo de sus vidas, las dirigentas han tenido que luchar para salir adelante. Una de las primeras barreras que les tocó enfrentar fue la culminación de su secundaria. El Instituto Nacional de Estadística e Informática (INEI), en su informe sobre las brechas de género (INEI 2017, 8183), nos recuerda que el Perú todavía tiene un $9 \%$ de mujeres analfabetas frente a un 2,9\% de hombres, situación que se agudiza si consideramos la variable de lengua materna nativa, con lo que la brecha se amplía hasta $26 \%$ de mujeres analfabetas frente a $6,2 \%$ de hombres. Todas las participantes en el proyecto, salvo una, culminaron la secundaria $\mathrm{y}$, actualmente, dos de ellas se encuentran cursando Derecho en una universidad estatal en Puno. En este sentido, se puede afirmar que casi todas las participantes pertenecen a la capa de mayor formación entre las hablantes de quechua y aimara.

Todas tienen una amplia experiencia como lideresas sociales y comunales. Han asumido diversos cargos (presidentas de federaciones de mujeres distritales, provinciales o regionales), han sido dirigentas de programas sociales, como los del vaso de leche, los comedores familiares y las iniciativas de promoción de la salud. También han sido secretarias de organización, de economía y de la mujer en diversas organizaciones. Por sus cargos, han sido convocadas por diversas instituciones para participar en procesos formativos y de desarrollo de capacidades dirigenciales. Una de ellas es SER, que no solo contribuyó en el desarrollo de su liderazgo, sino que, además, las involucró en sus equipos locales para que apoyaran procesos formativos en diversas comunidades, espacios en los cuales han ejercido el rol de 'traductoras sociales.'

Estas experiencias las han llevado a vincularse con las autoridades locales para exigir sus derechos y los de las asociadas de las organizaciones a las que representan, llegando a formar parte de los espacios de concertación de las municipalidades correspondientes. A lo largo de los años, estas 15 mujeres han jugado un rol muy importante como mediadoras interculturales, aunque muchas de ellas prefieren usar el término 'acompañantes,' ya que lo que hacen es justamente estar junto a la persona de habla originaria que requiere ayuda o apoyo para vincularse con alguna dependencia estatal. Más adelante, ilustraremos este punto a partir de sus propios testimonios.

Queremos resaltar la dimensión intercultural de su trabajo, ya que no solo median linguiísticamente entre la población rural quechuahablante o aimarahablante y el funcionariado de los diferentes servicios públicos, sino que, además, explican la dimensión cultural de lo que dicen las personas a las que acompañan. Este hecho es relevante en un país en el que, según la I Encuesta Nacional sobre Diversidad Cultural y Discriminación, existe aún una alta percepción de discriminación, que "es especialmente sentida por la población 
quechua o aimara (59\% de ellos), la afroperuana (59\%) y la población indígena o nativa amazónica (57\%)," siendo el idioma una de las causas de discriminación (Sanca Vega 2019, 10). Como señaló la CVR $(2003,316)$ en su informe final, "la tragedia que sufrieron las poblaciones del Perú rural, andino y selvático, quechua y asháninka, campesino, pobre y poco educado, no fue sentida ni asumida como propia por el resto del país; ello delata, a juicio de la CVR, el velado racismo y las actitudes de desprecio subsistentes en la sociedad peruana a casi dos siglos de nacida la República." De alguna manera, las dirigentas han contribuido a reducir la discriminación lingüística y cultural en los establecimientos públicos. Sin embargo, la discriminación y el racismo persisten y las dirigentas reportaron que han tenido que enfrentarlos una y otra vez en su rol de 'acompañantes.'

Como ejemplo, podemos citar el caso del Registro de Víctimas de las Esterilizaciones Forzadas (REVIESFO). Entre 1996 y 2000, se implementó en el Perú el Programa Nacional de Salud Reproductiva y Planificación Familiar, bajo la presidencia de Alberto Fujimori. En la aplicación de dicho programa, se esterilizó a miles de mujeres indígenas sin su consentimiento libre e informado, así como, en menor número, a varones, vulnerando sus derechos humanos. En 2015, el Estado peruano emitió un decreto supremo (N. ${ }^{\circ}$ 006/2015JUS), mediante el cual se declara de interés nacional la atención prioritaria a las víctimas de esterilizaciones forzadas en ese período y se crea el REVIESFO, a cargo del Ministerio de Justicia (MINJUS). El Grupo de Seguimiento a las Reparaciones a Víctimas de Esterilizaciones Forzadas (GREF), de la Coordinadora Nacional de Derechos Humanos, elaboró un informe en 2017 en el que se brindan detalles sobre el tema.

En la implementación del REVIESFO surgieron varios problemas. Uno de ellos fue que muchas de las víctimas procedentes de zonas altoandinas no hablaban castellano, por lo que reclamaban atención en su idioma. Frente a esta demanda, el MINJUS solicitó del MINCUL la intervención de intérpretes, que fue insuficiente para cubrir la demanda y resultó inapropiada, ya que se asignó el trabajo a varones. En este contexto, como respuesta a una solicitud del MINCUL, tres de las dirigentas fueron acreditadas puntualmente por SER como intérpretes y apoyaron en el proceso de inscripción de las víctimas. Esta experiencia no estuvo ajena a la discriminación que describen las participantes, ya que inicialmente las entidades estatales no les reconocían la acreditación. Además, no les permitían ingresar inmediatamente para acompañar a las víctimas, aduciendo que estas no necesitaban interpretación. Cuando salían, sin embargo, les indicaban a las dirigentas que no habían entendido bien lo que les habían dicho. Pese a estas dificultades, las tres culminaron su apoyo en el proceso exitosamente, porque, pese a las limitaciones, continuaron interpretando hasta que concluyó la campaña de registro.

Cabe reseñar que la mayoría de las participantes en el proyecto no han alcanzado el reconocimiento estatal, en tanto no han sido formadas para ejercer como intérpretes. De las 15 mujeres, solo una está inscrita en el Registro Nacional de Intérpretes y Traductores de Lenguas Indígenas u Originarias del MINCUL, después de completar el curso impartido por dicho organismo. Además de a la falta de esta validación, se enfrentan a otra barrera: la incertidumbre de que las dependencias públicas cuenten con recursos suficientes para contratar servicios de interpretación.

Podemos concluir que el rol que cumplen las 'acompañantes' transita entre la interpretación 'natural' y la oficial. Por su liderazgo, ejercen este rol en los diferentes espacios en los que se mueven cotidianamente, pero algunas también lo han desempeñado en ámbitos reglamentados. El interés teórico de esta distinción se expondrá en la siguiente sección.

\section{La interpretación no profesional o ad hoc: premisas teóricas}


La interpretación no profesional es, por definición, la forma más temprana de interpretación. A lo largo de la historia, personas bilingües o plurilingües, sin formación y sin remuneración, han ejercido de mediadores entre distintas comunidades lingüísticas. Los frutos de su labor son controvertidos. Por una parte, han posibilitado la comunicación intercultural, la colaboración y la transmisión de conocimientos. Por otra, han facilitado la colonización y la explotación comercial de pueblos y territorios a lo largo y ancho del mundo durante siglos. ${ }^{14}$

Desde que Harris (1973) acuñara el término traduction naturelle, el tema ha atraído la atención de expertos/as en distintas áreas. En un principio, fueron profesionales de la medicina quienes lo abordaron, seguidos de estudiosos con enfoques sociológicos y educativos. No sería hasta mediados de la década de 1990 cuando los/las especialistas en interpretación comenzaran a publicar trabajos de investigación relacionados con la interpretación no profesional. La publicación de un número especial de la revista The Translator en 2012 ("Non-Professionals Translating and Interpreting: Participatory and Engaged Perspectives") representa la consolidación de un campo emergente en los estudios de traducción e interpretación. Cabe reseñar, no obstante, que solo tres de los ocho artículos incluidos se centran en la interpretación (el primero, en el activismo en la interpretación; el segundo, en la interpretación eclesiástica; y el tercero, en la interpretación médica).

La implicación de intérpretes ad hoc en contextos regulados por las administraciones públicas es objeto de opiniones encontradas. Tradicionamente, se asume que en tales contextos el desempeño de intérpretes acreditados/as y sancionados/as por las autoridades competentes supone una garantía de calidad y confianza que no puede adjudicarse a los intérpretes 'naturales.' Sin embargo, incluso en ámbitos en los que existe regulación al respecto (por ejemplo, el marco europeo, Australia, EEUU, Canadá, Sudáfrica), existe un reconocimiento, más o menos tácito, de que la colaboración de familiares y conocidos es una realidad en sectores como los de salud o penitenciarías.

En este sentido, a partir de finales de la década de 1990 empiezan a publicarse estudios empíricos en los que se cuestionan los prejuicios mencionados respecto al ejercicio de la interpretación no profesional (e. g. Alexander, Edwards y Temple 2004; ElderkinThompson, Cohen Silva y Waitzkin 2001; Kuo y Fagan 1999; Martínez-Gómez 2016). Frente a una conceptualización académica convencional de las limitaciones, tanto linguiísticas como de conducta, que caracterizan tales intervenciones (cf. Meyer 2001; Pöchhacker y Kadric 1999, entre otros), dichos estudios arrojan resultados que muestran cómo la calidad de la interpretación debe contextualizarse desde la perspectiva de los/las participantes primarios/as en los encuentros mediados. Así, cuestiones referentes a la construcción de una dinámica comunicativa, la confianza y la afinidad cobran un protagonismo tradicionalmente reservado a parámetros como la precisión, la completitud y la dicción en contextos caracterizados por diferencias de estatus y poder (cf. Wadensjö [1998] 2014, capítulo 4). ${ }^{15}$ Como veremos, en el caso de las intérpretes naturales con quienes trabajamos, los criterios de la confianza y la afinidad son cruciales.

En la actualidad, la actividad de los/las intérpretes no profesionales (es decir, aquellos/as que no tienen una acreditación que avale su competencia) se ve rodeada de una nueva controversia. Como menciona Martínez-Gómez (2015, 205-206) en su exhaustiva panorámica bibliométrica de la interpretación no profesional desde sus albores, "[it] may be construed as contributing to endanger professionalization, especially in settings considered underdeveloped in that regard (e. g. community interpreting)." ${ }^{16}$ La profesionalización en cuanto a la interpretación comunitaria fue precisamente el tema del cuarto congreso de The Critical Link, el foro especializado en este tipo de interpretación más destacado, en 2004. Las actas del mismo (Wadensjö, Dimitrova y Nilsson 2007) revelan la tensión entre las prácticas reguladas, que implican la contratación de intérpretes acreditados/as, y las intervenciones ad 
hoc de personas bilingües, como personal de planta, familiares y amigos/as, para posibilitar la comunicación entre los/las representantes y los/las usuarios/as de servicios públicos cuando existe una brecha lingüística.

En el marco del estudio que nos ocupa, es importante establecer una distinción entre los/as intérpretes ad hoc descritos en la literatura, que cumplen su función como tales al margen de sus obligaciones habituales (empleados/as de servicios públicos) o para ayudar a personas concretas (familiares y amigos/as), y las participantes en nuestro proyecto, quienes perciben la mediación lingüística y cultural como una parte integral de su rol de liderazgo en las comunidades. No obstante, sus intervenciones para facilitar el entendimiento entre servidores públicos o representantes de instituciones oficiales (por norma, castellanohablantes) y los quechuahablantes y aimarahablantes de Ayacucho y Puno, cuyos niveles de competencia en el uso y la comprensión del castellano varían, se enmarcan en lo que en la literatura se denomina interpretación ad hoc. Las dirigentas, por tanto, serían intérpretes 'naturales,' ya que carecen de formación en materia de traducción o interpretación, no son remuneradas y actúan espontáneamente cuando las circunstancias lo requieren.

La controversia en relación con el estatus percibido de los/las intérpretes profesionales frente al de los/las no profesionales refleja una problemática más amplia en un contexto de colonialidad: la diferenciación entre los derechos lingüísticos y los derechos humanos lingüísticos. Según expone Skutnabb-Kangas (2006, 273-74), no todos los derechos lingüísticos se consideran derechos humanos lingüísticos. A diferencia de estos últimos, los primeros suelen estar recogidos en normativa internacional o nacional que no es vinculante (Martínez-Gómez 2018, 152). Un ejemplo es la Declaración Universal de Derechos Lingüísticos, o Declaración de Barcelona, de 1996, que, aunque contó con el apoyo técnico de la UNESCO, no fue ratificada por esta. Por ello, puede argumentarse que las intervenciones de los/las intérpretes ad hoc suplen carencias en la provisión oficial y legislada de servicios lingüísticos para sustentar los derechos humanos en materias como justicia, salud o educación. Algunas de estas carencias son inevitables, especialmente en países en desarrollo, como el Perú, donde la relativa escasez de recursos e infraestructura, además del elevado número de lenguas que se hablan en el país, obliga a priorizar el ejercicio de los derechos humanos lingüísticos recogidos en la legislación vinculante. ${ }^{17}$ Como ilustraremos, las dirigentas andinas que participaron en el proyecto desarrollan rutinariamente su labor de mediación en circunstancias en las que resultaría prácticamente imposible contratar los servicios de intérpretes registrados/as por el Estado.

\section{Los intérpretes ad hoc en el período colonial}

Los estudios sobre historia social en la colonia muestran la importancia que tuvieron los intérpretes oficiales en el funcionamiento de las estructuras políticas de Nueva España y el virreinato del Perú — los polos más importantes de relación con la metrópoli- del siglo XVI al XVIII. ${ }^{18}$ El ejercicio de este rol supuso un conjunto de beneficios, prerrogativas y márgenes de acción para algunos miembros de las nuevas elites indígenas coloniales, cuyas prácticas de mediación estaban institucionalizadas, eran rutinarias y remuneradas.

Sin embargo, había situaciones en las que estos intérpretes oficiales ('intérpretes generales' o 'intérpretes nombrados' por la administración judicial para causas específicas) no podían darse abasto o no contaban con los conocimientos lingüísticos requeridos para ejercer su rol, debido a la diversidad lingüística que prevalecía. Entonces, el sistema colonial, especialmente la administración de justicia, echaba mano de intérpretes ad hoc, que 
desarrollaban prácticas de mediación espontáneas, no institucionalizadas y habitualmente no remuneradas.

La mediación lingüística y cultural sin duda existió en territorios plurilingües y multiétnicos como el Tahuantinsuyo y el espacio mesoamericano antes de la conquista española, pero los datos escritos acerca de la interpretación en Hispanoamérica se remontan a las crónicas sobre los primeros contactos entre los hombres de Hernán Cortés y Francisco Pizarro y las poblaciones nativas de lo que luego serían Nueva España y el virreinato del Perú. Allí los españoles 'tomaron' indios (según el lenguaje de las fuentes históricas) para que actuaran de 'lenguas' o 'farautes.' Las figuras de Felipillo y de Doña Marina o Malintzin (Malinche, en su versión castellanizada) se asociaron a traición y doblez con el paso del tiempo (Valdeón 2014). En el caso del primero, la leyenda resalta, además, su supuesta torpeza en la explicación de los preceptos cristianos en la escena de Cajamarca, que en 1532 selló la derrota del imperio incaico a manos de los conquistadores. ${ }^{19}$ Estas percepciones constituyen un elemento de marcado contraste entre los primeros 'lenguas' coloniales y las participantes en nuestro estudio, quienes consolidan acumulativamente su rol de liderazgo y su sentido de pertenencia en sus respectivas comunidades mediante los actos de mediación lingüística y cultural que realizan.

En el siglo XVI, la percepción de ambigüedad, cuando no directa traición, respecto a los primeros 'lenguas' no solo se daba del lado de los indios, sino también de los españoles. La corona insistió repetidas veces en que era necesario que los españoles aprendieran las lenguas indígenas a fin de contar con intérpretes "más confiables" (Fossa 2006, 259, 270271). Con el paso del tiempo, sin embargo, indios y mestizos se imbricaron de distintas maneras en las jerarquías de la sociedad colonial y consolidaron su presencia en el oficio desde que este se constituyó como un cargo oficial ('intérprete general') en 1543, al crearse la Audiencia de Lima (Fossa 2006, 271). En la actualidad, sigue siendo excepcional en Hispanoamérica que los hablantes maternos de castellano y miembros de la sociedad mayor decidan aprender una lengua originaria y especializarse en ella lo suficiente para emprender cualquier tipo de interpretación entre ambos códigos. La norma es que los/las hablantes de lenguas indígenas que manejan también el castellano sean los/las responsables directos/as de estas mediaciones.

La literatura reciente ha seguido las trayectorias de algunos de los intérpretes oficiales en el siglo XVII y ha mostrado la profunda inserción que lograron tener en las estructuras letradas del poder colonial (De la Puente 2014; Huamanchumo 2016; Jurado 2010). De la Puente (2014) ha evidenciado que, en el tiempo de los Habsburgo, la influencia de algunos de estos actores podía ser incluso transatlántica. De hecho, para Ramos $(2011,30)$, el intérprete general llegó a estar entre los individuos más influyentes de la población indígena local en aquella centuria. De este modo, se ha abandonado la anterior visión de estos indios como sujetos atrapados en el limbo entre el mundo de los españoles y el de los indígenas, para pasar a verlos como "vital intermediaries whose command of Castillian helped bridge the gap between these two 'cultures" (De la Puente 2014, 158) ${ }^{20}$ La fluidez atribuida a estos actores coloniales para transitar entre los espacios implicados por la mediación caracteriza también a las dirigentas, a quienes, según sus propios discursos, se les atribuye una serie de saberes prácticos y estratégicos en sus comunidades.

De la Puente (2014) planteó una paradoja respecto a los intérpretes oficiales en la colonia: ¿cómo así uno o dos funcionarios, los intérpretes generales de la Audiencia de Lima, pudieron hacerse cargo de una atareada corte judicial que atendía casos provenientes de las más diversas regiones de los Andes multilingües? La respuesta ofrecida por el estudioso apunta al manejo de por lo menos tres lenguas por parte de los funcionarios: el castellano, un dialecto local de quechua o alguna otra lengua indígena, y la así llamada lengua general, una variedad quechua usada como lengua franca en la colonia (De la Puente 2014, 149; Durston 
2007). Sin embargo, como De la Puente observa, el multilingüismo andino colonial implicaba mucho más: existían diferentes variedades del aimara (sureñas y centrales), el puquina en el centro y en el sur, el mochica en la costa norte y, en los Andes norteños, por lo menos el culle. En teoría, manejar esta diversidad idiomática habría exigido mucho más del aparato judicial colonial que contar con uno o dos funcionarios trilingües.

Sugerimos que parte de la respuesta a este problema debe buscarse también en la acción de los intérpretes coloniales ad hoc, cuya actividad parece haber pasado inadvertida para los estudiosos. Estos nuevos 'lenguas' fueron autoridades indígenas, principalmente hombres versados en variedades locales del quechua o en alguna de las otras lenguas mencionadas anteriormente. Si ha sido difícil reconstruir las vidas de algunos de los intérpretes generales, dada la ausencia de documentos (Ramos 2011, 29-30), es posible imaginar cuán complejo será investigar las trayectorias de los intérpretes ad hoc teniendo en cuenta que, tal como las dirigentas contemporáneas, ejercían ese rol de manera esporádica e informal.

Sin embargo, podemos tener un atisbo de la importancia de las prácticas mediadoras 'naturales' para el funcionamiento de la justicia colonial si observamos una muestra de actos de interpretación desarrollados en una región acotada del virreinato peruano a lo largo de un período específico. En el Archivo Regional de Cajamarca, en los Andes norteños del Perú, hemos obtenido una muestra de actos interpretativos en los que participaron indígenas, a partir de la recopilación de casos judiciales correspondientes al siglo XVII en la colección Protector de Naturales (Andrade Ciudad y Bell 2017). En este corpus, observamos con cierta frecuencia interpretaciones esporádicas, muchas veces realizadas por los propios líderes indígenas y casi nunca remuneradas, en contraste con las mediaciones efectuadas por los intérpretes generales del corregimiento de Cajamarca y los nombrados oficialmente para las causas. En esta muestra no hemos observado ninguna interpretación realizada por una mujer.

Un caso representativo es el juicio llevado a cabo a inicios del siglo XVII por las propiedades que legó Beatriz de Escobar (1607), una mujer indígena 'principal,' en la localidad de Niepos, al oeste de la ciudad de Cajamarca. Si bien había un intérprete nombrado oficialmente para esta diligencia - Juan Bautista Valdés, quien interpretaba entre el quechua ("lengua general del ynga") y el castellano-, algunos de los declarantes asentados en Niepos solo hablaban mochica ("yunga"). Por esta razón, cuando las autoridades judiciales llegaron a Niepos, junto con Valdés, en setiembre de 1611, debieron realizar las diligencias primero con los indígenas que sabían quechua o eran 'ladinos' en castellano, y luego solicitarle al cacique local, Cristóbal Chuquinboques, que, después de su declaración, pasara a actuar de intérprete en los actos llevados a cabo en castellano y mochica. Chuquinboques — quien era supuestamente trilingüe en quechua, mochica y castellanodelegó después este rol en su teniente de alcalde, Seuastian Tamta Vico, y ambos interpretaron a tres testigos indios.

Observamos en este caso una dificultad del Estado colonial, incluso con su administración relativamente descentralizada, para manejar la realidad multilingüe de su territorio. A pesar de que el aparato judicial español afianzó el quechua como lengua de comunicación con los indígenas, algunas zonas mantuvieron sus lenguas originarias sin transitar totalmente al castellano, por lo menos en el siglo XVII, por lo cual se requirió de interpretaciones ad hoc cuando los intérpretes oficiales no conocían los códigos locales. Tal vez esta fue la principal motivación, junto con la necesidad planteada por la propia legislación colonial de garantizar el 'debido proceso' de los acusados, para emplear a mediadores lingüísticos empíricos en este período.

Vemos que, tal como en el presente, los intérpretes ad hoc en el pasado contribuyeron a llenar los vacíos del aparato estatal para la provisión de justicia. Notamos, asimismo, un contraste entre el lugar destacado que ocuparon los intérpretes oficiales y la falta de 
reconocimiento y remuneración de los intérpretes ad hoc en la colonia, que se repite actualmente entre traductores-intérpretes registrados por el MINCUL y mediadores espontáneos como las participantes en el proyecto. ${ }^{21}$ La experiencia del REVIESFO mostró las brechas entre las 'acompañantes' y los intérpretes estatales, como ya hemos señalado. Esta jerarquía se observa también en contextos de consulta previa, en los que es frecuente que, por su desconfianza ante el Estado, las comunidades indígenas soliciten contar con sus propios intérpretes, a causa de un rechazo hacia el/la intérprete oficial. En estas situaciones se crean nuevas jerarquías entre ambos tipos de actores, que, como hemos reseñado en estudios previos (Andrade Ciudad, Howard y de Pedro Ricoy 2019; de Pedro Ricoy, Howard y Andrade Ciudad 2018), se basan en el reconocimiento estatal o su ausencia, una preparación técnica básica en el oficio o su total inexistencia y la confianza (o no) por parte de las poblaciones involucradas.

\section{La labor de las intérpretes ad hoc: estudio de caso}

Las entrevistas que llevamos a cabo en Ayacucho y Puno con las 15 lideresas bilingües nos permitieron conocer su labor. ${ }^{22}$ Nos dimos cuenta de la variedad de situaciones en las cuales se necesita una intervención suya para facilitar la comprensión, tanto lingüística como cultural, entre los miembros de sus comunidades aimarahablantes y quechuahablantes, por un lado, y los/las funcionarios/as castellanohablantes con quienes tienen que interactuar cotidianamente, por otro. ${ }^{23}$

Al preguntarles a las lideresas cuál fue su primera experiencia como traductora, en varios casos, mencionaron la experiencia de haber vivido la época de violencia política que sacudió de manera particular las regiones de donde ellas provienen. Nos contaron cómo habían tenido que mediar lingüísticamente, bien con los miembros de Sendero Luminoso, bien con los militares, para tratar de prevenir abusos. Otros contextos de intervención citados fueron las asambleas, las visitas de funcionarios/as castellanohablantes del exterior de la comunidad, proyectos de desarrollo y campañas de salud. Con frecuencia se aludió a su mediación en el ámbito médico, sobre todo consultas obstétricas y partos. Otro ámbito común es el de justicia: interacciones con agentes de la Policía, trámites burocráticos de toda índole y quejas por violencia intrafamiliar, además de las campañas del REVIESFO en el caso de tres dirigentas. Pasamos a examinar una selección de sus testimonios con referencia a algunos de estos contextos, considerados según las premisas teóricas que hemos planteado.

Aurora, una lideresa bilingüe quechua-castellano de 52 años de edad, que pertenece a la Federación de Mujeres Indígenas de Ayacucho, nos explicó así la necesidad de traducir y la percepción que ella tiene de la práctica: ${ }^{24}$

El mismo hecho de que hay esa necesidad de traducir del castellano al quechua y del quechua al castellano ha hecho de que nosotras, sin darnos cuenta, nos hemos convertido en traductoras. Yo, al participar en las reuniones, al estar en las asociaciones, en las organizaciones de base, pues, tenía que hablar en las dos lenguas [...] porque había personas que un poco entendían en castellano y otros en quechua. Porque en nuestras comunidades, en nuestros distritos, hay líderes, lideresas, que ya vuelven de la ciudad, y otros que son retornantes, y que los hijos ya no han utilizado el idioma quechua. Entonces, en ellos, es necesario hablar en las dos lenguas. Así que, sin darnos cuenta, como le digo, nos convertimos en traductoras [sonríe] (Aurora, Ayacucho, 24 de marzo de 2018).

Comenta con satisfacción que la situación de bilingüismo estructural en la cual ella vive y trabaja hace que necesariamente tenga que manejar sus dos lenguas, quechua y castellano, en 
espacios formales. Hace referencia específica a los 'retornantes', término que en el contexto ayacuchano alude a la emigración masiva durante los años del conflicto armado interno, que, a su regreso, con frecuencia mostraban un perfil sociolingüístico generacional cambiado.

La observación repetida de Aurora sobre cómo "sin darnos cuenta nos hemos convertido en traductoras" es de interés particular en este artículo. De hecho, esta observación se deriva de su participación en el proyecto, que le hizo entender que su actividad de mediadora bilingüe tiene un nombre y merece ser reconocida y valorada por la sociedad. Planteamos este tema en el curso de todas las entrevistas y las reacciones fueron variadas. Por ejemplo, cuando le preguntamos a Cristina (de la Federación de Mujeres Indígenas de Ayacucho, 45 años, bilingüe castellano-quechua) si ellas llamaban 'traducción' a su actividad, respondió de la siguiente manera:

En sí lo llamamos como una intervención [...]. Supongamos que voy a un trámite, un pago o un algo. Entonces, hay personas que están allí hablando en quechua y [el empleado] no les entiende y les dice: "Ay no, pero señora, no, que esto, yo no sé," en ese plan, un poco que no quieren, pues, a pesar que saben, a pesar que entienden, pero no lo quieren atender (Cristina, Ayacucho, 26 de marzo de 2018).

Describe cómo puede intervenir al encontrarse en una situación como esta, cuando ve que hay resistencia de parte del funcionariado a atender correctamente a una persona que no sabe comunicarse en castellano. En su ejemplo, la situación de vulneración de los derechos linguiísticos se agudiza por el hecho de que el empleado que menciona entendía quechua, pero no quería demostrarlo. Cristina utiliza la palabra 'intervención' y, en otros momentos de la entrevista, 'ingresar' y 'apoyar,' para describir este tipo de mediación espontánea cuando surge la necesidad. En sus palabras: "No es que vamos y nos quedamos allí [esperando] que vengan, no, sino que aparecemos en su momento" (Cristina, Ayacucho, 26 de marzo de 2018). Esta explicación se refiere a que el apoyo con la traducción es espontáneo: no están esperando a que aparezca una persona para traducir, sino que responden al percatarse de la necesidad. Su explicación ilustra la diferencia entre actuar de manera imprevista según lo requieran las circunstancias y ser 'acompañante,' como en otras experiencias que ha tenido en el curso de su trabajo de lideresa, en las que actuó de mediadora de manera más sistemática:

Cuando trabajé como coordinadora allá [en Huancavelica], en ese entonces ya era parte de mi trabajo. Yo tenía que recepcionar a todos los comuneros, a los presidentes comunales, a todas las autoridades. Entonces, algunos hablaban castellano. [...] Como lideresa, siempre hemos estado en eso, apoyando a las señoras, a las mamitas, o cuando venían de acá la RENIEC o cuando venían de la ONPE ${ }^{25}$ más que nada, en la época de las elecciones (Cristina, Ayacucho, 26 de marzo de 2018).

Explicó que, como lideresa, vigilaba el proceso electoral, asegurando que se dejara pasar a las señoras que acudían a votar, a pesar de que el funcionario que controlaba el proceso decía que no las entendía cuando hablaban quechua e intentaba impedir su entrada. Al distinguir entre la mediación que hace como parte de su rol de lideresa y el apoyo que ofrece en situaciones espontáneas, la entrevistada enfatiza que en el último caso lo hace a título personal y no porque sea su deber profesional:

Como persona, para mí, no porque es parte de mi profesión, sino porque a mí me da eso de ayudar, de apoyar, entonces [...] ¿qué le digo? No seremos traductoras, ¿qué se dice?, reconocidas, nada, sino que somos traductoras empíricas tal vez (Cristina, Ayacucho, 26 de marzo de 2018). 
En otro momento de la entrevista, Cristina resume la informalidad de su actuación en marcos no institucionalizados diciendo "Ni siquiera sabíamos que éramos traductoras," observación que corrobora el testimonio de Aurora antes mencionado.

En cuanto a la buena voluntad a la cual alude su testimonio, Cristina afirma que "todo lo hemos hecho por amor." Confirma que es un trabajo no remunerado, pero que, sin embargo, "me fortalece espiritualmente bastante." Aunque estas declaraciones suyas puedan parecer una idealización, proponemos que ejemplifican un discurso de afectividad y compañerismo que caracteriza muchos de los testimonios. ${ }^{26}$ Lidia (lideresa ayacuchana bilingüe quechua-castellano de 43 años, de la organización de Club de Madres y del Comité de Vaso de Leche de su distrito) nos brinda otro ejemplo en quechua ayacuchano o chanka:

Chay punchawmanta ñuqa gustawan ayudayta runata. Mana yachaspapas rimani maypipas, y rimasaqmi maypipas warmikunata ayudanaypaq ñuqa. Hinaptinmi yachani gracias papayrayku mamayrayku kay kichwa rimayta ñuqa. [...] Chaymi ñuqa ayudani chay traducispa, ñuqa ayudani hermanaykunata ñuqa necesitaptin. [...] Wasiyman hamunku naptin niwan: "Señora Lidia, doctorman richkani, ¿manachu kumpañaykuwankiman?” imatapis ruwachkaptiypas dejaruni y pasani paykunata ayudanaypaq. [Desde ese día me gusta ayudar a la gente. Sin saber hacerlo, hablo en donde sea. Y hablaré en donde sea para ayudar a las mujeres. Así, yo sé hablar quechua gracias a mi papá y a mi mamá. [...] Por eso yo ayudo traduciendo a mis hermanas cuando me necesitan. [...] Vienen a mi casa y me dicen: "Señora Lidia, estoy yendo al médico, ¿no me acompañarías?" Yo dejo rápido lo que estoy haciendo para ayudarlas a ellas] (Lidia, Ayacucho, 24 de marzo de 2018).

Sus palabras expresan el reconocimiento que perciben las dirigentas por parte de sus comunidades, particularmente de las mujeres ("mis hermanas"). La entrevistada demuestra, así, una clara vivencia de gratificación por sentirse útil para su gente.

En términos generales, las entrevistadas se entusiasmaron al saber que la propuesta del proyecto era hacer conocer su labor de mediación. De manera particular, Aurora y Cristina expresaron satisfacción con la calificación de 'traductora,' que las ayuda, según entendemos, a sentirse afirmadas en el rol. Otras, en cambio, nos precisaron que no se identifican con este apelativo. Por ejemplo, cuando le preguntamos a Laura (presidenta de la asociación de mujeres de su provincia, de 41 años, bilingüe quechua-castellano) cómo se había iniciado en la práctica de la 'traducción', nos aclaró:

La traducción nosotros le decimos aquí 'acompañamiento,' porque cuando yo asumí como secretaria, primera vez en mi barrio, siempre hay hermanas que venían del campo, ¿no? Entonces, yo hablaba correctamente de quechua, ¿no? Entonces íbamos al municipio, y a veces hay profesionales que en ese municipio que trabajan, no saben hablar quechua, no saben traducir. Entonces, yo hacía ese acompañamiento. Yo les decía en quechua: "Haku risunchis ñuqawan. ¿Imapaqtaq munashanki? ¿Imapitaq yanapasqayki? Haku risunchis chaypi chay funcionariowan ñuqawan tramitaramusunchis, " ñispa ñuqa kumpañaq kani rimanakunapaq." ["Vamos conmigo, ¿para qué estás queriendo? ¿En qué te ayudaré? Vamos conmigo y allí haremos el trámite con el funcionario," diciendo, yo las acompañaba para que hablaran entre sí]. (Laura, Puno, 6 de abril de 2018)

Laura explica cómo facilitaba los trámites que tenían que efectuar las mujeres quechuahablantes del campo ('hermanas') con los funcionarios hispanohablantes de la Municipalidad. Conceptualiza este apoyo, expresado con el verbo quechua yanapay 
('ayudar'), como un acto de solidaridad y no como una tarea explícitamente lingüística. Su objetivo es rimanakunapaq ("para que hablaran entre sí"), utilizando en quechua el sufijo de acción recíproca $n a k u .{ }^{27}$ Así, presenta su rol como una facilitación de la comunicación.

La mediación cultural es otro aspecto importante. En muchas ocasiones, a las dirigentas les corresponde explicar la lógica cultural del discurso de las personas a las que acompañan y, a veces, tienen que aclarar algunas actitudes de las personas quechua- o aimarahablantes que las autoridades castellanohablantes no llegan a entender. Carla (tesorera de una organización nacional de mujeres, 47 años, bilingüe quechua-castellano) cuenta el caso de una mujer que se había negado a ir al hospital para dar a luz en su segundo parto por la experiencia negativa que había tenido en el primero, una decisión que le costó la vida:

Esta señora en su primer parto había ido a un hospital con su creencia de no quitarse el sombrero, de no sacarse la falda y el personal de salud la... la fuerza en realidad a sacar la falda y quitarle el sombrero. Entonces, eso ha hecho que a ella... ese derecho que ella tenía a sus creencias ancestrales, a su vestimenta, su idioma... realmente la pisotearon. Eso ha hecho que esta mujer no vaya ya en el segundo parto a un hospital, porque no se entendía. El médico habla castellano, es de otro lugar, de Ica, de aquí de Ayacucho, de Lima; son médicos de estos lugares, y una paciente que era esta mujer que solo hablaba quechua y con sus costumbres... Claro, al médico o al personal de salud nos forman de distinta manera en la universidad. No nos forman quizás en sus costumbres del paciente o de la paciente. Entonces, eso ha hecho que ha habido un choque entre dos culturas distintas (Carla, Ayacucho, 24 de marzo de 2018). ${ }^{28}$

En el curso de su labor de intérpretes ad hoc, tal vez por su misma naturaleza informal, a veces las dirigentas reportaron que encuentran resistencia a su intervención por parte de las autoridades. Sin embargo, en los testimonios que mencionan el tema, la razón no es la falta de acreditación profesional, como podría esperarse según la literatura especializada, sino por la falta de lazos de parentesco con la persona a quien están acompañando. Así lo explica Blenda (presidenta de la organización de mujeres de su centro poblado, de 42 años, bilingüe aimara-castellano):

Muchas veces en las oficinas y en otros lugares te dicen: “Tú, ¿qué sabes?” O sea, no te valoran. “¿Cómo, qué, tú? ¿Por qué le acompañas? ¿Qué eres? ¿Es tu familia? No es tu familia," te dicen, ¿no? Entonces... a las hermanas que vienen, que son las futuras traductoras, yo digo: "No hay que tener miedo, porque nosotros [...] no somos reconocidas, pero hay que tener fuerza y seguir adelante" (Blenda, Puno, 8 de abril de 2018).

Es paradójico que las intérpretes ad hoc de nuestro estudio a veces encuentren rechazo porque les faltan lazos de parentesco con las personas a quienes buscan apoyar. Esta situación es la inversa a la que se da en los contextos donde existe una cultura de interpretación más reglamentada, en los que los códigos institucionales excluyen la participación de familiares o personas conocidas en situaciones oficiales. Si, por ejemplo, un(a) paciente o la víctima de una agresión acude a sus familiares para que actúen como intérpretes, la norma es que estos se vean rechazados por carecer de capacitación y por ser susceptibles a conflictos de interés. En el otro lado de la balanza, como ya se comentó, tratándose de interpretación comunitaria, los parámetros de confianza y de afinidad — como lo es el parentesco - son tenidos en cuenta, tanto por los/las profesionales como en el ámbito académico.

En esta sección hemos visto que de las dirigentas bilingües de nuestro estudio se espera una interpretación ad hoc en muchas circunstancias, la mayoría de las cuales están 
asociadas a su labor de liderazgo. Ellas mismas distinguen entre la intervención espontánea y la mediación más formal, estando esta última relacionada con su actividad profesional. A diferencia de la ambivalencia que caracterizaba a los intérpretes en el período colonial, las dirigentas se sienten reafirmadas como lideresas de sus organizaciones y como miembros de sus comunidades mediante las actividades de mediación lingüística y cultural que realizan. El discurso que comparten todas se resume en las palabras de Cristina, quien afirmó: "Nos gustaría que todo esto se revalore.”

\section{Conclusiones}

Nuestra colaboración con las dirigentas y con la ONG que apoya su labor, SER, así como los intercambios que mantuvimos con instituciones y miembros del público, nos han proporcionado diferentes perspectivas émicas y éticas referentes a la problemática que rodea el rol de las intérpretes ad hoc en el Perú. Estas perspectivas permiten evaluar lo que sería una situación ideal (plena cobertura de las lenguas originarias en el contexto de los servicios públicos) frente a la realidad de una coyuntura social, económica y política en la que los derechos lingüísticos pueden verse vulnerados por diferentes motivos. Uno de ellos concierne directamente al tema de este artículo: el hecho de que, mediante la participación de intérpretes capacitados/as o la formación en el bilingüismo del funcionariado pertinente, el Estado peruano todavía no logra garantizar plenamente esos derechos a los hablantes de las 48 lenguas originarias habladas en el país, si bien la garantía de los derechos humanos linguiísticos está contemplada en la legislación nacional y hay diversas acciones recientes orientadas a su cumplimiento. ${ }^{29}$ En circunstancias imprevistas o emergencias y, sobre todo, en la cotidianidad, el rol de las dirigentas indígenas como intérpretes ad hoc resulta crucial para posibilitar la comunicación interlingüística e intercultural.

En primer lugar, es destacable que las dirigentas entendieran las labores de mediación linguiística y cultural que realizan como parte integral de su labor y no como una actividad profesionalizada. La participación en nuestro proyecto estimuló su reflexión al respecto, con distintas consecuencias: manifestaron diferentes actitudes en cuanto a su autoidentificación como 'traductoras' y a la profesionalización del rol.

Resulta interesante también la diferencia entre las actitudes del funcionariado en el Perú (según las describen ellas), que a veces rechaza la intervención de las dirigentas como intérpretes ad hoc porque no tienen lazos de parentesco con la persona a la que atienden, y las del funcionariado en países en los que hay códigos de conducta que estipulan que la interpretación la deben llevar a cabo intérpretes acreditados/as y, por tanto, excluyen la interpretación por parte de familiares o conocidos/as, aunque, en determinados contextos se reconozca como una realidad. Así, entendemos que la práctica de las dirigentas en la región andina se encuadra en un enfoque culturalmente marcado de la interpretación en el ámbito de los servicios públicos, donde el parentesco tiene una importancia particular.

Por otra parte, es comprensible que los miembros de las comunidades indígenas sientan una afinidad especial con las dirigentas que les prestan apoyo en sus encuentros con el funcionariado, sean o no sus familiares o amigas. Ellas respaldan esta relación de afinidad mediante alusiones a su autoidentificación étnica y comunitaria. En este sentido, se puede establecer un paralelo con lo que ocurre en procesos de consulta previa (Andrade Ciudad, Howard y de Pedro Ricoy 2019; Flemmer 2018; de Pedro Ricoy, Howard y Andrade Ciudad 2018), en los que las comunidades indígenas a menudo cuentan con intérpretes locales además de los/las que proporciona el Estado por una cuestión de confianza.

No se pueden ignorar las similitudes y diferencias observables entre la práctica de interpretación ad hoc que llevan a cabo las dirigentas en la actualidad con la que se desarrolló 
durante la colonia. Aunque estas relaciones deberían estudiarse de manera más detallada en el futuro, entre las semejanzas cabe destacar que en ambos contextos temporales la interpretación ad hoc llena vacíos estatales, especialmente en el ámbito de salud y en cuanto al acceso a la justicia, y que la llevan a cabo miembros de la elite indígena (indígenas 'principales' en la colonia y la capa de mayor formación entre las mujeres hablantes de quechua y aimara en el presente). Lo que contrasta con el periodo colonial es que, en la actualidad, son mujeres, y no solo hombres, las que asumen ese rol y que, según sus propios testimonios, gozan de reconocimiento y aceptación en sus comunidades, lejos de la percepción ambigua que rodeaba (y aún rodea) la actividad de los antiguos 'lenguas.'

El Perú está realizando avances en cuanto al reconocimiento de los derechos lingüísticos de sus comunidades originarias e implementando medidas para garantizarlos. Sin embargo, la falta de recursos humanos y financieros, así como de estructuras administrativas e infraestructura adecuada hacen imposible actualmente garantizar una plena cobertura de servicios de traducción e interpretación en el ámbito de los servicios públicos. Así, aventuramos que las labores de mediación intercultural que llevan a cabo las mujeres que participaron en el proyecto y otras muchas dirigentas de los Andes continuarán siendo una realidad. Por ello, para concluir, debemos señalar la importancia de la formación personal en la dirigencia comunitaria para el ejercicio de la mediación intercultural en el Perú. Esta formación implica un empoderamiento individual y una reflexión constante en torno a la identidad étnica y lingüística que resultan cruciales para el ejercicio del rol. Sumados a la experiencia en el manejo de asuntos relacionados con la violencia de género, representan una plataforma idónea para que las dirigentas desempeñen el papel de intérpretes ad hoc y de esta manera contribuyan al acceso a los derechos humanos para miembros de sus comunidades que, sin su intervención, se enfrentarían a barreras lingüísticas y culturales difíciles de superar.

\section{Agradecimientos}

Agradecemos al Consejo de Investigación para las Artes y Humanidades del Reino Unido (Arts and Humanities Research Council, AHRC) la financiación del proyecto de investigación en el que se basa este artículo mediante su parte del Fondo de Investigación para Retos Globales (Global Challenges Research Fund, GCRF). Este proyecto está dentro del marco de atención a las Metas de Desarrollo Sostenible de la ONU.

Agradecemos también la inestimable colaboración del equipo del Lugar de la Memoria, la Tolerancia y la Inclusión Social (LUM) en Lima (Perú) y del Grupo Yuyachkani, que hicieron posibles las actividades de difusión pública del proyecto.

Finalmente, agradecemos a Lee Anthony Bendezú Bendezú por su apoyo en el registro fotográfico y videográfico de las actividades relacionadas con el proyecto, y al historiador Nicanor Domínguez Faura por su información sobre el caso de interpretación en Niepos.

\section{Notas}

1. La capacitación y acreditación de traductores e intérpretes indígenas en el Perú es coordinada por el Ministerio de Cultura desde 2012. En el mismo año, se creó por Resolución Viceministerial (N. ${ }^{\circ}$ 001-2012- VMI-MC) un Registro Nacional de Interpretes y Traductores de Lenguas Indígenas u Originarias, que se oficializó mediante Decreto Supremo (N. ${ }^{\circ} 002-$ 2015) tres años después. Los integrantes del Registro desempeñan una valiosa labor para 
facilitar a los hablantes de las estimadas 48 lenguas originarias que existen en el Perú el acceso a derechos humanos en áreas como salud, justicia y educación. Cuando se requiere una mediación lingüística y cultural en el ámbito de los servicios públicos, las entidades de la administración deben recurrir al Registro, que es una herramienta útil también para organizaciones privadas.

2. La Asociación Servicios Educativos Rurales es una ONG con 39 años de experiencia de trabajo en zonas rurales del Perú, en especial con mujeres indígenas, dedicada a la promoción de los derechos humanos y al fortalecimiento de la gobernabilidad democrática.

3. Sería materia de un estudio posterior observar en qué medida los dirigentes varones también realizan este tipo de mediación.

4. Se entiende 'colonialidad' aquí como la definió Quijano $(2014,285)$ : “uno de los elementos constitutivos y específicos del patrón mundial de poder capitalista," originado y mundializado a partir de América, que se fundamenta en la imposición de una clasificación racial-étnica de la población, y que "opera en cada uno de los planos, ámbitos y dimensiones, materiales y subjetivas, de la existencia cotidiana y a escala social."

5. La época colonial en el Perú se extiende desde el siglo XVI hasta las primeras décadas del siglo XIX, cuando el país se independizó de España. Una abundante literatura desde el marco de la colonialidad del poder sostiene que muchas de las estructuras heredadas de ese período persisten bajo diversas formas hasta el presente (véase Quijano [1992, 2014]).

6. En este artículo utilizamos ambos términos como sinónimos.

7. Reunión de proyecto, 23 de agosto de 2018.

8. Para una interpretación del significante 'hermanos del campo' en el discurso de los traductores-intérpretes estatales, véase Andrade, Howard y de Pedro Ricoy (2018). En nuestro corpus actual también aparecen formulaciones similares.

9. Se realizó una convocatoria a 20 dirigentas de organizaciones de mujeres que han mantenido vínculo con SER durante más de 15 años, quienes son bilingües y han desarrollado labores de interpretación. Finalmente, 15 mujeres pudieron participar en el proyecto.

10. La obra teatral trilingüe (castellano, quechua y aimara) Warmipa simin - Warmina arupa (Voces de mujeres) es un trabajo original que se desarrolló y escenificó, con las dirigentas como protagonistas, en colaboración con el grupo Yuyachkani. Se estrenó en Lima el 11 de noviembre de 2018 y la grabación de la representación se exhibió en Ayacucho y Puno con el apoyo de SER en octubre de 2019. La exposición audiovisual Yanapaqkuna / Yanapirinaka / Acompañantes. Traductoras indígenas por una sociedad más justa estuvo alojada en el Lugar de la Memoria, la Tolerancia y la Inclusión Social (LUM), en Lima, desde diciembre de 2018 hasta junio de 2019. El material audiovisual permanece disponible en Internet, en la página web del LUM:

https://lum.cultura.pe/cdi/busqueda/documentos?field_rb_colecciones_tid\%5B\%5D=18601. 11. El técnico audiovisual también se encargó del registro fotográfico. Una selección del mismo se incluyó en la exposición, patrocinada por el LUM y, junto con los videos, forma parte del repositorio digital alojado en el archivo del LUM.

12. Los fragmentos en quechua y aimara fueron subtitulados en castellano para la exposición celebrada en el LUM.

13. Para un desarrollo preliminar de los aspectos relativos a la interpretación en el marco del trabajo de la CVR, véase Howard, de Pedro Ricoy y Andrade Ciudad (2018, 31-32), y de Pedro Ricoy y Andrade Ciudad (en prensa).

14. En el caso que nos ocupa, la interpretación ad hoc sirve para salvar la brecha linguística y cultural que existe entre las instituciones oficiales y las comunidades indígenas en el Perú contemporáneo. 
15. En situaciones de interpretación ad hoc, los participantes primarios tienden a valorar la compenetración con el/la intérprete como instrumento para facilitar la comprensión por encima de los parámetros que regulan la interpretación profesional.

16. "puede interpretarse como un factor que contribuye a poner en peligro la profesionalización, especialmente en contextos que se consideran infradesarrollados a este respecto (p. ej., la interpretación comunitaria)."

17. Hay que señalar que se están desarrollando iniciativas a favor de los derechos lingüísticos, como la educación intercultural bilingüe (EIB) y la acreditación de servidores públicos como hablantes de lenguas indígenas en diversos ámbitos de las administraciones locales.

18. La amplia bibliografía sobre el tema incluye los trabajos de De la Puente 2014, Durston 2007, Fossa 2006, Ramos 2011, Valdeón 2014 y Yannakakis 2008. En un sentido más amplio de la traducción cultural en los Andes, destaca el trabajo de Harrison 1989.

19. Entre los traductores e intérpretes de lenguas indígenas y castellano formados recientemente por el Estado peruano (Andrade Ciudad, Howard y de Pedro Ricoy 2018, 2019), hemos encontrado reminiscencias de este personaje. En concreto, un traductorintérprete del quechua ayacuchano o chanka recuerda haberse inspirado en Felipillo y su compañero Martinillo al representar a un intérprete judicial en una obra de teatro que abordaba las violaciones de mujeres en las décadas del conflicto armado interno. Este personaje se caracterizaba por su indiferencia ante el dolor de las víctimas y su parcialización con un sistema de justicia no solo ajeno a las demandas de estas, sino que, además, las revictimizaba. El personaje fue descrito así: "Alguien neutro, más o menos como Felipillo y Martinillo, más bien tirando casi al poder. El poder te habla en castellano. Entonces, alguien que está en el medio, frío..." (entrevista, 28/07/2015).

20. "intermediarios vitales cuyo manejo del castellano ayudó a cerrar las brechas entre estas dos "culturas."”

21. Hay que reconocer que este contraste solo se da en el terreno del reconocimiento institucional, pues, en cuanto a remuneración y condiciones laborales, la realidad presente es muy desafiante para la mayoría de los traductores-intérpretes indígenas. Asimismo, los traductores-intérpretes de las lenguas más habladas (el quechua y el aimara) tienen, en general, más oportunidades laborales que los de lenguas minoritarias. De cualquier forma, son muy excepcionales (aunque sabemos que existen) los casos de aquellos que pueden limitar su actividad laboral a la traducción-interpretación.

22. Los extractos de entrevistas son tomados de grabaciones filmadas en los lugares de residencia de las dirigentas en Ayacucho y Puno.

23. Véase el trabajo de Schneider (2015) basado en su estudio etnográfico de la práctica de traducción, primordialmente oral, entre el quechua y el castellano desarrollada por mujeres indígenas, que actuaban, por ejemplo, como intérpretes jurídicas y como mediadoras en situaciones cotidianas. Según su análisis, esta práctica "revela el poder transformador de la labor creativa [llevada a cabo por las mujeres bilingües] de la formación de identidad y la comprensión mutua, que trasciende los discursos hegemónicos, la desigualdad y las ideologías lingüísticas" ("[it] reveals the transformative power in [the bilingual women's] creative labor of identity formation and mutual understanding, transcending hegemonic discourses, inequality and linguistic ideologies" [Schneider 2015, 235]).

24. Nos referimos a las entrevistadas con seudónimos por razones de confidencialidad. 25. RENIEC: Registro Nacional de Identificación y Estado Civil; ONPE: Oficina Nacional de Procesos Electorales.

26. Es probable que este discurso sea, por lo menos en parte, un efecto de la presencia de los entrevistadores. 
27. La palabra rimanakunapaq es estructuralmente ambigua en quechua: también puede querer decir "para que habláramos todos entre nosotros" y "para que habláramos yo (la participante) y el funcionario;" sin embargo, por el contexto, entendemos que el significado es "para que hablen entre sí (el funcionario y la beneficiaria)." En cualquier caso, la presencia del sufijo - naku- indica que el acto de comunicación se realiza recíprocamente. Este elemento de acción recíproca refleja una noción importante de la comprensión local (la 'etnometapragmática') de la comunicación intercultural en los Andes.

28. En las comunidades andinas, el sombrero es un componente de la identidad de la persona. Que una persona le quite a otra el sombrero sin su permiso se sentiría como un agravio. En Cajamarca se han recopilado los siguientes testimonios entre campesinos: "Parece que la honra del sombrero viene porque es la primera prenda que uno empieza a ponerse en la cabeza. Yo creo que todo es honra, si es una camisa también es honra, porque te cubre el cuerpo. Pero el sombrero es mucho más por que [sic] te cubre la cabeza, porque todo empieza por la cabeza, entonces es una honra principal [...]. Quitar el sombrero es un pecado más grave que quitar otra prenda. En la cabeza andamos todos los conocimientos y de allí está más cerca al sombrero y por eso es más pecado" (Proyecto Enciclopedia Campesina 1990, 19).

29. El reconocimiento oficial de los funcionarios bilingües forma parte del programa de certificación de competencias que está desarrollando el Estado peruano (https://www.sineace.gob.pe/se-forma-nueva-promocion-de-evaluadores-de-servidorespublicos-bilingues/). Sobre la acción de los intérpretes capacitados por el Estado, véase De Pedro Ricoy, Howard y Andrade Ciudad (2018).

\section{Referencias}

Alexander, Claire, Rosalind Edwards y Bogusia Temple. 2004. Access to Services with Interpreters: User views. York: Joseph Rowntree Foundation/York Publishing Services.

Andrade Ciudad, Luis y Martha G. Bell. 2016. "Mapping Colonial Quechua through Trial Interpretations in 17th-Century Cajamarca." Colonial Latin American Review 25 (4): 445-464.

Andrade Ciudad, Luis, Rosaleen Howard y Raquel de Pedro Ricoy. 2018. "Activismo, derechos lingüísticos e ideologías: La traducción e interpretación en lenguas originarias en el Perú." Indiana 35 (1): 139-163. https://journals.iai.spkberlin.de/index.php/indiana/article/view/2487

Andrade Ciudad, Luis, Rosaleen Howard y Raquel de Pedro Ricoy. 2019. "Traduciendo culturas en el Perú: Los derechos lingüísticos en la práctica.” En Diversidad y contacto, editado por Marleen Haboud, 513-554. Quito: Pontificia Universidad Católica del Ecuador.

CVR (Comisión de la Verdad y Reconciliación). 2003. Informe final. Lima: Presidencia del Consejo de Ministros.

De la Cadena, Marisol. 2004. Indígenas mestizos: raza y cultura en el Cusco. Lima: Instituto de Estudios Peruanos.

De la Puente Luna, José Carlos. 2014. "The Many Tongues of the King: Indigenous Language Interpreters and the Making of the Spanish Empire." Colonial Latin American Review 23 (2): 143-170.

De Pedro Ricoy, Raquel, Rosaleen Howard y Luis Andrade Ciudad. 2018. "Walking the Tightrope: The Role of Peruvian Indigenous Interpreters in Prior Consultation Processes." Target 30 (2): 187-211. 
De Pedro Ricoy, Raquel y Luis Andrade Ciudad. En prensa. "Translation and Interpreting in the Indigenous Languages of Peru: A contemporary perspective." En Oxford Handbook of Translation and Society, editado por Christine Ji. Oxford: Oxford University Press.

Durston, Alan. 2007. Pastoral Quechua. The history of Christian translation in Colonial Peru, 1550-1650. Notre Dame, IN: University of Notre Dame Press.

Elderkin-Thompson, Virginia, Roxane Cohen Silver y Howard Waitzkin. 2001. "When nurses double as interpreters: A study of Spanish-speaking patients in a U.S. primary care setting." Social Science and Medicine 52: 1343-1358.

Flemmer, Riccarda. 2018. "Stuck in the Middle: Indigenous Interpreters and the Politics of Vernacularizing Prior Consultation in Peru." The Journal of Latin American and Caribbean Anthropology 23 (3): 521-540.

Fossa, Lydia. 2006. Narrativas problemáticas. Los inkas bajo la pluma española. Lima: Fondo Editorial de la Pontificia Universidad Católica del Perú / Instituto de Estudios Peruanos.

GREF (Grupo de Seguimiento a las Reparaciones a Víctimas de Esterilizaciones Forzadas). 2017. "Esterilizaciones forzadas durante el conflicto armado interno." En Informe Anual de la Coordinadora Nacional de Derechos Humanos 2015-2016, 54-61. Lima: CNDDHH. http://derechoshumanos.pe/2017/04/informe-anual-2015-2016/

Harris, Brian. 1973. "La traductologie, la traduction naturelle, la traduction automatique et la sémantique." Cahiers de linguistique 3: 133-146. https://www.erudit.org/en/journals/cl/1973-n2-cl3104/800013ar/

Harrison, Regina. 1989. Signs, Songs and Memory in the Andes: Translating Quechua Language and Culture. Austin: University of Texas Press.

Howard, Rosaleen. 2009. "Beyond the Lexicon of Difference: Discursive Performance of Identity in the Andes." Latin American and Caribbean Ethnic Studies 4 (1): 17-46.

Howard, Rosaleen, Raquel de Pedro Ricoy y Luis Andrade Ciudad. 2018. "Translation Policy and Indigenous Languages in Hispanic Latin America." International Journal of the Sociology of Language 251: 19-36.

Huamanchumo de la Cuba, Ofelia. 2016. "El oficio de lengua de un indio bilingüe de Chachapoyas. Perú-Siglo XVI.” Revista del Instituto Riva-Agüero 1 (1): 39-76.

INEI (Instituto Nacional de Estadística e Informática). 2017. Perú: Brechas de Género 2017. Avances hacia la igualdad de mujeres y hombres. Lima: INEI. https://www.inei.gob.pe/media/MenuRecursivo/publicaciones_digitales/Est/Lib1444/li bro.pdf

Jurado, M. Carolina. 2010. "Don Pedro de Dueñas, indio lengua. Un estudio de caso de la interpretación lingüística andino-colonial en el siglo XVII." Anuario de Estudios Hispánicos, Archivísticos y Bibliográficos 16: 285-309.

Kuo, David y Mark J. Fagan. 1999. "Satisfaction with Methods of Spanish Interpretation in an Ambulatory Care Clinic." Journal of General Internal Medicine 14: 547-550.

Martínez-Gómez, Aída. 2015. "Bibliometrics as a tool to map unchartered territory: A study on non-professional interpreting." Perspectives: Studies in Translatology 23 (2): 205222.

Martínez-Gómez, Aída. 2016. "Facing Face: Non-Professional Interpreting in Prison Mental Health Interviews.” European Journal of Applied Linguistics 4 (1): 93-115.

Martínez-Gómez, Aída. 2018. "Language, translation and interpreting policies in prisons: Protecting the rights of speakers of non-official languages." International Journal of the Sociology of Language 151: 151-172.

Meyer, Bernd. 2001. "How Untrained Interpreters Handle Medical Terms." En Triadic 
Exchanges: Studies in Dialogue Interpreting, editado por Ian Mason, 87-106.

Manchester: St. Jerome.

Pöchhacker, Franz y Mira Kadric. 1999. "The Hospital Cleaner as Healthcare Interpreter: A Case Study." The Translator 5 (2): 161-178.

Proyecto Enciclopedia Campesina. 1990. Trenzando sombras. Los sombreros en la tradición cajamarquina. Serie "Nosotros Los Cajamarquinos" 7. Cajamarca: Asociación para el Desarrollo Rural de Cajamarca.

Quijano, Aníbal. 1992. "Colonialidad y modernidad / racionalidad.” Perú Indígena 13 (29): 11-20.

Quijano, Aníbal. 2014. "Colonialidad del poder y clasificación social.” En Cuestiones y horizontes: De la dependencia histórico-estructural a la colonialidad / descolonialidad del poder, editado por Danilo Assis Clímaco, 285-327. Buenos Aires: Consejo Latinoamericano de Ciencias Sociales (CLACSO).

Ramos, Gabriela. 2011. "Language and society in Early Colonial Peru." En History and Language in the Andes, editado por Paul Heggarty y Adrian J. Pearce, 19-38. Nueva York: Palgrave Macmillan.

Sanca Vega, Ingrid. 2019. Mujeres rurales en el Perú. Indicadores claves para una vida digna. Lima: ILC/ SER.

Schneider, Antonia. 2015. "'Translating women': gender and translation as cultural practice in Huancavelica/Peru." En Las agencias de lo indígena en la larga era de la globalización. Microperspectivas de su producción y representación desde la época colonial temprana hasta el presente (Estudios Indiana 7), editado por Romy Köhler y Anne Ebert, 235-256. Berlin: Ibero-Americanisches Institut Preussischer Kulturbesitz/Gebr. Mann Verlag.

Skutnabb-Kangas, Tove. 2006. "Language Policy and Linguistic Human Rights." En Introduction to Language Policy: Theory and Method, editado por Thomas Ricento, 273-291. Hoboken: Wiley-Blackwell.

Susam-Sareva, Sebnem y Luis Pérez-González, eds. 2012. "Non-Professionals Translating and Interpreting: Participatory and Engaged Perspectives." The Translator Special Issue 18 (12).

Valdeón, Roberto. 2014. Translation and the Spanish Empire in the Americas. Ámsterdam: John Benjamins.

Wadensjö, Cecilia. [1998] 2014. Interpreting as Interaction. Londres: Routledge.

Wadensjö, Cecilia, Birgitta Englund Dimitrova y Anna-Lena Nilsson, eds. 2007. The Critical Link 4: Professionalisation of Interpreting in the Community. Ámsterdam: John Benjamins.

Yannakakis, Yanna. 2008. The art of being in-between: Native intermediaries, Indian identity, and local rule in colonial Oaxaca. Durham: Duke University Press. 